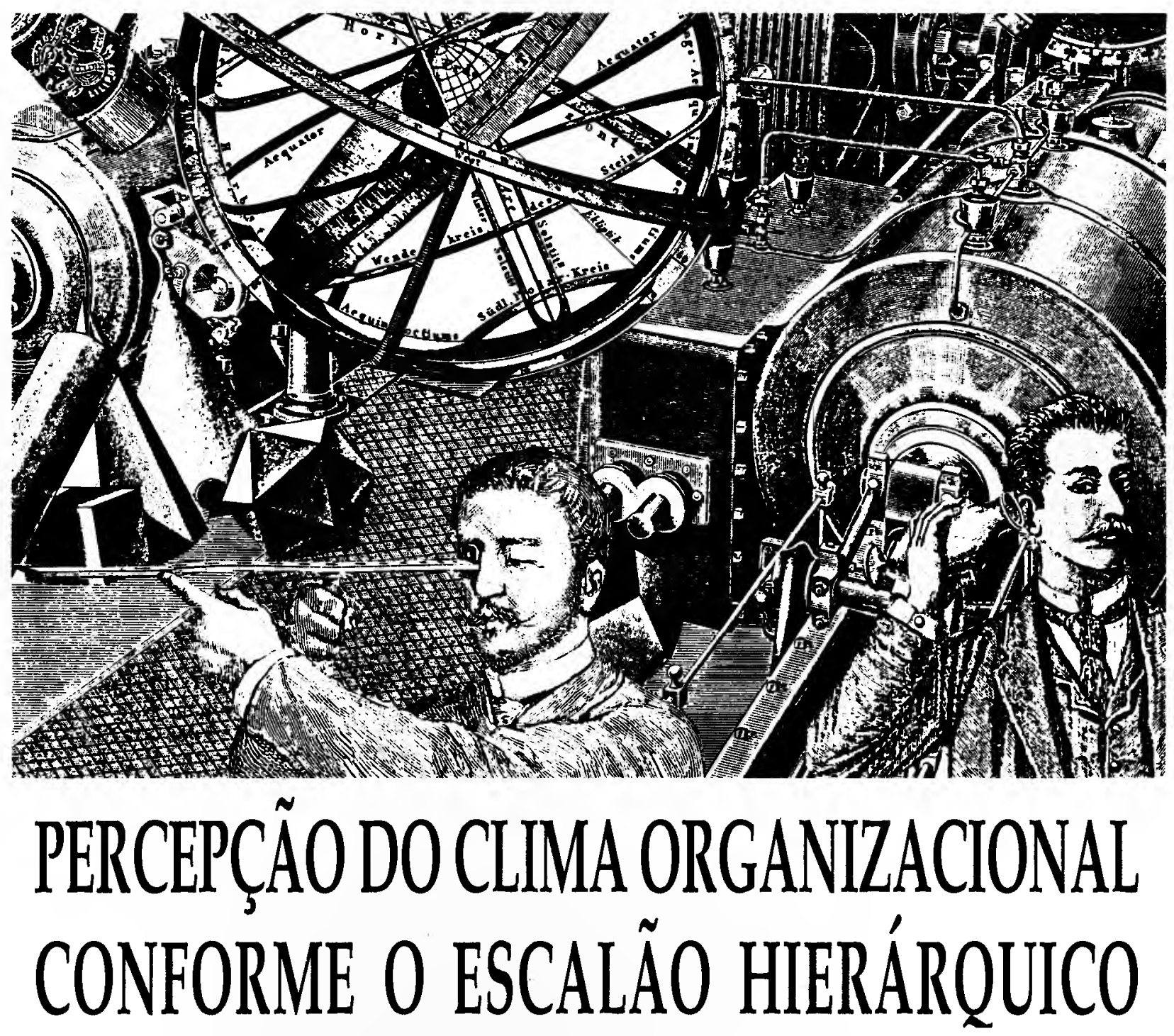

INTRODUÇÃO

- LUIZ HOMERO SILVA GUTIERREZ

Professor do Programa de Pós-Graduação e Administração da Universidade Federal do Rio Grande do Sul, da Pontifícia Universidade Católica (PUC-RJ) e Gerente Geral de Recursos Humanos de J.H. Santos.

Este trabalho foi desenvolvido em consonância com as linhas de pesquisa do Programa de Pós-Graduação da Universidade Federal do Rio Grande do Sul e sob orientação da Prof ${ }^{3}$ Dra. Edela Lanzer Pereira de Souza.
A rapidez dos acontecimentos no mundo moderno está forçando os homens públicos, os cientistas, os dirigentes de empresas e todos os responsáveis pelos diversos setores da vida social a uma atitude de compreensão, abertura e adaptação às rápidas transformações que ocorrem no mundo de hoje, as quais são incompatíveis com a rigidez e com modelos ultrapassados.

Referindo-se à necessidade de acompanhar as mudanças, Basil e Cook consideram que "as organizações requerem flexibilidade em sua estrutura e estratégias adequadas se quiserem sobreviver e ser viáveis nas próximas décadas. Assim, os governos, as instituições e a coordenação internacional devem criar o meio ambiente 
apropriado para permitir que os individuos $e$ as organizaçōes prosperem $e$ criem os frutos da civilizaçäo" (1).

Neste sentido, a célebre expressão latina, tempora mutantur, nos et mutamur inillis (os tempos estão mudados e nós somos mudados dentro deles), aplica-se tanto ao homem do passado como ao do século XX.

As considerações feitas acima evidenciam a necessidade de entender como as pessoas componentes de qualquer organização percebem as múltiplas mudanças que ocorrem tanto ao nível de ambiente externo como no interior da própria organização e como reagem a elas.

Destacam-se, como um importante auxílio para o manejo e administração das situaçð̄es de mudança e engajamento das pessoas na organização, os estudos que vêm sendo realizados sobre o clima organizacional.

A respeito disso, diz Souza:

"É importante que o administrador compreenda o conceito de clima organizacional, porque é através de sua criação que ele pode manejar a motivação de seus empregados. A eficiência da organização pode ser aumentada através da criação de um clima organizacional que satisfaça as necessidades de seus membros $e$, ao mesmo tempo, canalize esse comportamento motivado na direção dos objetivos organizacionais" (2).

São apresentados neste trabalho os resultados de uma pesquisa realizada no período de fevereiro a junho de 1983, em uma empresa industrial gaúcha, com o objetivo de detectar a percepçáo de seu clima organizacional pelos integrantes dos distintos níveis hierárquicos segundo os quais ela se estrutura.

\section{METODOLOGIA UTILIZADA}

Utiliza-se aqui o conceito de clima, tal como foi formulado por Forehand e Gilmer: "clima é - conjunto de características que descrevem uma organização, distinguindo-a das demais, mantendo-se relativamente permanente $e$ influenciando o comportamento de seus participantes" (3).

A escala utilizada para mensurar o clima foi a de Kolb (4), baseada nos estudos de Litwin e Stringer (5), que tem sido aplicada sem maiores problemas no Brasil, por Souza ${ }^{(6)}$, Haetinger ${ }^{(7)}$ e Gutierrez ${ }^{(8)}$.

Em termos de motivação, foi adotado o referencial de McClelland que, procurando identificar as dimensões componentes da motivação humana, considerou três motivos sociais principais que atuam nas pessoas. Os motivos básicos revelados são: de afiliação, poder e realização. $O$ motivo de afiliação pressupõe a necessidade de o indivíduo manter relações interpessoais estreitas com os demais. São pessoas que valorizam mais o contato social do que as tarefas e a produtividade. São queridas pelo grupo, e o sentimento de rejeição lhes é muito penoso. $O$ motivo de poder se caracteriza pelo desejo de exercer influência e impacto sobre os outros, bem como leva as pessoas a valorizarem a autoridade (normas e líderes), quer como chefe quer como subordinado.

O motivo de realização distingue os indivíduos pela sua necessidade de procurar alcançar sua auto-realização através da tarefa. São pessoas que tendem sempre a fazer o melhor possivel em suas atividades. Preferem trabalhos criativos a tarefas rotineiras. Procuram proporse objetivos difíceis, embora realizáveis, para

1. BASIL, Douglas e COOK, Curtis. O Empresário diante das transformações sociais, econômicas e tecnológicas. Såo Paulo, McGraw-Hill do Brasil, 1978, pg. 03.

2. SOUZA, Edela L.P. "Percepção do Clima Conforme o Escalăo Hierárquico" in: Revista de Administração de Empresas, Rio de Janeiro, vol. 20, $\mathrm{n}^{2} 4$, out/dez., 1980, p. 27.

3. FOREHAND, Garlie A. e GILMER, B. von Haller. "Environmental variations in studies of organizational behavior" in: Psychological Bulletin, Baltimore, 62: 361-382, 1964.

4. KOLB, David; RUBIN, I. e McINTYRE, J. Psicologia Organizacional: uma abordagem vivencial. São Paulo, Atlas, 1978.

5. LITWIN, G.H. e STRINGER, R.A. Jr. Motivation and Organizational Climate. Boston, Harvard University Press, 1968.

6. SOUZA, Edela L.P. Clima e Cultura Organizacionais, como se manifestam e como se manejam. São Paulo, Edgar Blücher, 1978.

7. HAETINGER, Yolanda F. Influência da Eficácia de Liderança no Clima Organizacional Percebido e Desejado em uma Entidade Hospitalar de Porto Alegre. Dissertação de Mestrado, PUC-RS, 1979.

8. GUTIERREZ, Luiz Homero S. Clima Organizacional como Instrumento de Levantamento de $\mathrm{Ne}$ cessidades de Recursos Humanos.Tese de Mestrado, PPGA-UFRGS, 1983. 
Quadro 1: Níveis Hierárquicos Pesquisados

\begin{tabular}{lcl}
\hline Nivel Hierárquico & Pop. Total & Pop. Pesqulsa (N) \\
\hline Chefes & 09 & 09 \\
Assessores & 10 & 10 \\
Supervisores Mensalistas & 20 & 20 \\
Supervisores Horistas & 16 & 16 \\
Funcionários Mensalistas & 196 & 15 (amostra) \\
Funcionários Horistas & 450 & 15 (amostra) \\
Total & 700 & 84
\end{tabular}

que seus esforços e capacidades venham a influir nos resultados, evitando o risco de fracasso. $O$ dinheiro é valorizado na medida em que serve de parâmetro para sua realização.

Os sete fatores de clima propostos por Kolb correspondem aos motivos sociais básicos de McClelland ${ }^{(9)}$, conforme exposição abaixo:

\section{Fatores Constitutivos do Clima}

1. Conformidade com estrutura

2. Responsabilidade

3. Padrão de desempenho

4. Recompensa

5. Clareza organizacional

6. Apoio e calor humano

7. Liderança

Perguntas que testam os fatores de clima associados aos motivos sociais básicos de McClelland foram respondidas em uma escala tipo Likert de 10 pontos, onde se obteve o clima atual e o desejado (ideal), bem como a discrepância entre ambos.

Apresenta-se no Anexo 10 instrumento utilizado, buscando-se esclarecer o que e como foi respondido.

A pesquisa foi realizada em uma organização industrial que, resumidamente, caracteriza-se por atuar na área de caldeiraria pesada, desenvolvendo projetos principalmente para órgãos e instituições governamentais.

A empresa mencionada é de origem familiar e germânica, tendo 20 anos de existência e 700 funcionários; é dirigida pelo seu fundador, que se vê motivado, por força da idade, a passar a gestão dos negócios a seus filhos e a profissionais que formariam um sistema misto de gestão. Tal perspectiva de mudança e transição motiva a realização desta pesquisa.

Os dados obtidos através do instrumento de Kolb foram coletados em março de 1983 e referem-se a seis níveis hierárquicos distintos, conforme se vê no Quadro 1.
A amostra foi testada de forma a assegurar-se a precisão desejada nas estimativas de médias, de modo que se a pode considerar significante . ( $95 \%$ de confiança).

Também foi feita uma análise de variância que se encontra junto aos dados nas Tabelas 1, 2 e 3.

Após a aplicação do instrumento onde os indivíduos só identificam seu nível hierárquico, tabularam-se os dados e realizaram-se entrevistas individuais com todos os participantes.

A entrevista propriamente dita teve as seguintes características:

- Individual

- Semi-estruturada

- Realizada nas salas dos entrevistados e/ou do pesquisador

- Sigilosa

- Registrada com caneta e papel na presença do entrevistado

- Sem tempo pré-determinado, mas durando em média 40 minutos

-Proporcionou feedback mútuo

Através das entrevistas buscou-se obter mais dados sobre os motivos das dimensões de clima encontradas.

\section{ANÁLISE DOS RESULTADOS}

Nas Tabelas 1, 2 e 3 encontram-se, respectivamente, as médias do clima real, as do clima ideal e a diferença entre ambos, de acordo com os diferentes níveis hierárquicos e os sete fatores pesquisados.

9. MCCLELLAND, David. Studies in Motivation. New York, Appliton-Century-Crofts, 1955. 
Tabela 1: Clima Atual (Real) Conforme Percepcão do Nível Hierárquico

\begin{tabular}{lccccccc}
\hline \multicolumn{1}{c}{ Fatores } & $\begin{array}{c}\text { Chefe } \\
\text { Divisão }\end{array}$ & Assessores & $\begin{array}{c}\text { Superv. } \\
\text { Mensalistas }\end{array}$ & $\begin{array}{c}\text { Superv. } \\
\text { Horistas }\end{array}$ & $\begin{array}{c}\text { Func. } \\
\text { Mensalista }\end{array}$ & $\begin{array}{c}\text { Func. } \\
\text { Horista }\end{array}$ & $\bar{M}$ \\
\hline Conformidade $^{\text {Responsabilidade }}$ & 6,12 & 6,00 & 6,41 & 6,50 & 7,29 & 6,66 & 6,49 \\
Padrós $^{*}$ & 4,87 & 4,20 & 4,94 & 6,85 & 6,35 & 5,16 & 5,39 \\
Recompensa $_{\text {Clima Organiz.** }}^{*}$ & 3,75 & 5,10 & 5,52 & 5,64 & 6,76 & 5,33 & 5,35 \\
Apoio & 4,75 & 3,40 & 6,35 & 5,50 & 5,76 & 5,33 & 5,18 \\
Liderança* $^{4,00}$ & 3,30 & 5,00 & 5,71 & 6,76 & 6,16 & 5,15 \\
& 6,25 & 6,00 & 6,88 & 6,00 & 5,29 & 5,00 & 5,90 \\
& 4,62 & 4,00 & 5,94 & 6,57 & 5,82 & 6,25 & 5,53 \\
& 4,90 & 4,57 & 5,86 & 6,11 & 6,29 & 5,69 & 5,57 \\
\hline
\end{tabular}

Níveis de Significância: $0,05\left(^{*}\right)$

$0,01\left({ }^{* 4}\right)$

Tabela 2: Clima Ideal Conforme Percepção do Nivel Hierárquico

\begin{tabular}{|c|c|c|c|c|c|c|c|}
\hline Fatores & $\begin{array}{l}\text { Chefe } \\
\text { Divisão }\end{array}$ & Assessores & $\begin{array}{c}\text { Superv. } \\
\text { Mensalistas }\end{array}$ & $\begin{array}{l}\text { Superv. } \\
\text { Horistas }\end{array}$ & $\begin{array}{c}\text { Func. } \\
\text { Mensalista }\end{array}$ & $\begin{array}{l}\text { Func. } \\
\text { Horista }\end{array}$ & $\overline{\bar{M}}$ \\
\hline $\begin{array}{l}\text { Conformidade } \\
\text { Responsabilidade } \\
\text { Padrőes* } \\
\text { Recompensa* } \\
\text { Clima Organiz. } \\
\text { Apoio } \\
\text { Liderança }\end{array}$ & $\begin{array}{l}5,37 \\
7,87 \\
7,87 \\
7,50 \\
8,75 \\
8,25 \\
7,87\end{array}$ & $\begin{array}{l}5,30 \\
7,60 \\
8,50 \\
8,80 \\
9,10 \\
8,40 \\
8,90\end{array}$ & $\begin{array}{l}6,47 \\
8,05 \\
8,17 \\
8,47 \\
8,82 \\
8,58 \\
8,11\end{array}$ & $\begin{array}{l}5,71 \\
7,71 \\
6,35 \\
6,64 \\
7,92 \\
7,92 \\
7,64\end{array}$ & $\begin{array}{l}5,94 \\
7,70 \\
7,64 \\
8,41 \\
8,64 \\
8,52 \\
8,05\end{array}$ & $\begin{array}{l}5,58 \\
8,08 \\
7,66 \\
8,08 \\
8,75 \\
9,16 \\
8,00\end{array}$ & $\begin{array}{l}5,72 \\
7,83 \\
7,69 \\
7,98 \\
8,66 \\
8,47 \\
8,09\end{array}$ \\
\hline & 7,64 & 8,08 & 8,09 & 7,12 & 7,84 & 7,90 & 7,77 \\
\hline
\end{tabular}

Níveis de Significância: 0,05 (")

$0,01(* *)$

Tabela 3: Diferença Entre Clima Atual e Ideal Conforme Percepção do Nível Hierárquico

\begin{tabular}{lccccccc}
\hline \multicolumn{1}{c}{ Fatores } & $\begin{array}{c}\text { Chefe } \\
\text { Divisão }\end{array}$ & Assessores & $\begin{array}{c}\text { Superv. } \\
\text { Mensalistas }\end{array}$ & $\begin{array}{c}\text { Superv. } \\
\text { Horistas }\end{array}$ & $\begin{array}{c}\text { Func. } \\
\text { Mensalista }\end{array}$ & $\begin{array}{c}\text { Func. } \\
\text { Horista }\end{array}$ & $\bar{M}$ \\
\hline Conformidade $^{*}$ & 0,75 & 0,70 & 0,05 & 0,78 & 1,35 & 1,08 & 0,75 \\
Responsabilidade $^{* *}$ & 3,00 & 3,40 & 3,11 & 0,85 & 1,35 & 2,91 & 2,32 \\
Padróss $^{* *}$ & 4,12 & 3,40 & 2,64 & 0,71 & 0,88 & 2,33 & 2,11 \\
Recompensa* $_{\text {Clima Organiz. }}^{* *}$ & 2,75 & 5,40 & 2,11 & 1,14 & 2,64 & 2,75 & 2,64 \\
Apoio & 4,75 & 5,80 & 3,82 & 2,21 & 1,88 & 2,58 & 3,26 \\
Liderança* $^{2,00}$ & 2,40 & 1,70 & 1,92 & 3,23 & 4,16 & 2,57 \\
& 3,25 & 4,90 & 2,17 & 1,07 & 2,23 & 1,75 & 2,38 \\
& 3,43 & 4,33 & 2,60 & 1,44 & 1,93 & 2,50 & 2,29 \\
\hline
\end{tabular}


Quadro 2: Ordem dos Fatores Motivacionals por Grupo Hierárquico (10)

\begin{tabular}{|c|c|c|c|}
\hline \begin{tabular}{|ll} 
Nivel Hlerárqulco & Motlvos \\
\end{tabular} & Aflilação & Poder & Realização \\
\hline $\begin{array}{l}\text { Chefe de Divisão } \\
\text { Assessores } \\
\text { Superv. Mensalistas } \\
\text { Superv. Horistas } \\
\text { Funcionários Mensalistas } \\
\text { Funcionários Horistas }\end{array}$ & $\begin{array}{l}2^{2} \\
2^{2} \\
2^{2} \\
1^{2} \\
1^{2} \\
1^{2}\end{array}$ & $\begin{array}{l}3^{2} \\
3^{9} \\
3^{2} \\
3^{9} \\
2^{9} \\
3^{9}\end{array}$ & $\begin{array}{l}1^{2} \\
12 \\
12 \\
2^{2} \\
3^{2} \\
2^{9}\end{array}$ \\
\hline Clima Global & $1^{2}$ & $3^{2}$ & $2^{9}$ \\
\hline
\end{tabular}

Agrupando-se os índices conforme a motivação envolvida nos sete fatores, obtiveram-se os dados constantes do Quadro 2.

As informações obtidas nas entrevistas são mencionadas na discussão e recomendações que seguem:

O trabalho revelou a existência de dois grupos distintos na percepção do clima, na motivação e na satisfação. $O$ primeiro é constituído pelos chefes de divisão, assessores e supervisores mensalistas; o segundo grupo é formado por supervisores horistas, funcionários mensalistas $e$ horistas.

Os resultados são discutidos de acordo com a realidade específica de cada nível hierárquico, bem como a dos dois grandes grupos acima mencionados.

As comparações feitas entre os fatores constitutivos do clima e/ou os grupos hierárquicos estudados, têm por base as percepções de clima (real e ideal) descritas nas tabelas 1, 2 e 3.

Observando-se a hierarquia existente na organização estudada, os cargos (abaixo de diretoria) analisados são os seguintes:

\section{CHEFES DE DIVISÃO}

Em todas as dimensões o clima ideal é superior ao atual (real) que, em média, está na metade da escala $(4,90)$, enquanto que o ideal está no grau 7,64.

Quanto à percepção do clima real, o fator "padrões" é o que alcança o ponto mais baixo na escala $(3,75)$; é também em relação a essa variável que se encontra a segunda maior diferença $(4,12)$ entre a percepção do clima real e o nível de aspiração dos chefes de divisão.

Quanto ao fator "responsabilidade", é interessante observar que os niveis de maior poder dentro da organização (chefes de divisão, assessores, supervisores mensalistas) se sentem, no momento da pesquisa, com os mais baixos níveis de responsabilidade e com altos índices no sentido de obtê-la (clima ideal). Nas suas sugestões, obtidas nas entrevistas, mencionam a necessidade de definição de organograma e critérios de atuação e desempenho.

O item "clareza organizacional", por sua vez, é o que contém o índice mais baixo de todos na descrição do clima atual $(5,15)$, e o mais alto na descrição do clima ideal $(8,66)$, isto é, é o que apresenta a maior discrepância entre a situação vivida e a desejada.

Confirma-se aqui um dos "dez pecados capitais das empresas familiares" mencionados por Sprüngli (11), que é o de "não determinar objetivos precisos".

Alie-se a essa falta de clareza de objetivos e prioridades a necessidade de definição da estrutura da empresa, o que é apontado principalmente pelo grupo de chefes de divisão, assessores e supervisores mensalistas.

\section{ASSESSORES}

Em todas as dimensões, o clima ideal é supe-

10. A ordem dos fatores motivacionais por grupo hierárquico foi obtida pela soma das divergências do clima atual/real, associando os fatores de Kolb aos motivos de McClelland. Assim, exemplificando a classificação do motivo de poder, somaram-se os fatores de "conformidade com a estrutura" e "liderança" obtendo-se uma média que após foi comparada classificatoriamente com os demais motivos (realização e aplicação) por grupo hierárquico.

11. SPRÜNGLI, Rudolf R. "Os Pecados Capitais das Empresas Familiares" in: Dirigente Industrial, São Paulo, 2(20):38-40, março, 1979. 
rior ao atual (real) que, em média, está quase na metade da escala $(4,57)$, enquanto o ideal está em 8,08. Quanto à percepção do clima real, o índice mais baixo de resposta entre todas as variáveis refere-se à "clareza organizacional" $(3,30)$. Esta variável também apresenta a maior diferença $(5,80)$ entre a percepção real e o nível de aspiração dos assessores.

Dizem Basil e Cook que "um ingrediente básico do clima organizacional é o sistema de recompensas e puniçōes. Pode resultar em inovaçóes $e$ no alcance de objetivos ou, alternativamente, precipitar a apatia $e 0$ afastamento. Em muitos casos, força os administradores a competiçōes políticas pessoais do tipo ganharl perder" (12).

Os achados realmente confirmam a importância do sistema de recompensas na percepção do clima, visto que esse fator apresenta a segunda maior diferença entre o clima real e o ideal, em todos os níveis pesquisados.

\section{SUPERVISORES MENSALISTAS}

Em todas as dimensões, o clima ideal é superior ao atual (real), que, em média, está um pouco acima da metade da escala $(5,86)$ enquanto o ideal está em 8,09.

Quanto à percepção do clima real, o índice mais baixo de resposta entre todas as variáveis é obtido pelo fator "responsabilidade" $(4,94)$, sendo encontrada, também em relação a esta variável, a segunda maior diferença $(3,11)$ entre a percepçăo real e o nível de aspiração dos supervisores mensalistas.

Quanto à "conformidade", os supervisores mensalistas apresentam a menor diferença entre real e ideal, tendo-se em vista que, basicamente, reivindicam possibilidade maior de po-der e ação, enquanto que seus subordinados diretos, os funcionários mensalistas, apresentam a maior diferença neste mesmo fator, sentindo-se desinformados e insatisfeitos com o excesso de normas e procedimentos.

Será que neste relacionamento supervisorsubordinado está presente a lei de Parkinson (13), que diz que o chefe, quando tem dúvida ou quer manter ou aumentar seu poder, passa a criar procedimentos e normas burocráticas desnecessárias? Ou será que é um atributo característico da empresa em estudo? Ou, ainda, pelo fato de a empresa estar no que chamaríamos "processo de crescimento" conforme descrito por Greiner (14)?

Payne e Mansfield (15), Waters (16) e outros constataram que uma conformidade maior com as normas melhorava a sociabilidade. No presente trabalho, do nível de supervisão para cima, os respondentes apresentaram relação entre os fatores conformidade e calor humano/ apoio; o que confirma a constatação dos autores supra citados.

\section{SUPERVISORES HORISTAS}

Em todas as dimensões, o clima ideal é superior ao atual (real), que, em média, está quase um ponto acima da metade da escala $(6,11)$ enquanto o ideal está no grau 7,12 . Quanto à percepção do clima real, o fator "recompensa" é o que apresenta o índice mais baixo de resposta $(5,50)$, sendo encontrada, também em relação a esta variável, a terceira maior diferença $(2,11)$ entre a percepção real e o nível de aspiração dos supervisores mensalistas.

Para os supervisores horistas, a característica da empresa no que se refere ao fator "liderança", percebida e expressa por seus membros, é a acentuada dependência de seu "dono".

A maioria das colocações feitas foram no sentido de obtenção de maior poder de decisão e ação, bem como de definições de papéis. WATSON afirma que "o papel desempenhado pelos formadores da organização e o contexto onde 17.

12. BASIL, Douglas e COOK, Curtis. Op. cit., pp. 16-

13. PARKINSON, C. Northcote. A Lei de Parkinson, na sociedade, na política, nos negócios. São Paulo, Pioneira, 1975.

14. GREINER, Larry E. "Evolution and Revolution as Organizations Grow" in: Harvard Business Review, Uxbredge, July-August, 1972, p. 77.

15. PAYNE, Roy e MANSFIELD, Roger. "Relationship of perceptions of organizational climate to organizational structure, context and hierarchical position" in: Administrative Science Quarterly, Uthach, N.Y., 18(4): 515-526, Dec., 1973.

16. WATERS, L.; ROACH, D. e BATLIS, N. "Organizational climate dimensions and job-related attitudes" in: Personnel Psychology, Baltimore, 27:465-476, 1974.

17. WATSON, Thomas. "The Business and its Believes" in: International Business Machines apud SIMI, J.A. Análise Organizacional, Manual de Treinamento e Desenvolvimento, São Paulo, McGraw-Hill do Brasil, 1980, cap. 29. 
ocorrem seus primeiros passos influem decisivamente na compreensa da história $e$ do momento atual da organizaçao" (17).

Essas consideraçб̃es săo reforçadas pelos achados da pesquisa, que podem ser amplificados por uma sugestão dada por alguns supervisores horistas. Dizem eles: "Deviamos ter mais do que um chefe, porque se um dia nos faltar o paträo, acho que pára tudo".

Souza, revisando a bibliografia sobre clima e cultura, constata ser "o estilo gerencial mais freqüentemente mencionado como determinante do clima e da cultura" (18).

Litwin e Stringer (19) encontraram diferentes atuações dos subordinados, em função do estilo de liderança adotado pelo chefe. Já Haetinger (20) constatou que os subordinados ineficazmente liderados apresentam uma diferença maior entre o clima organizacional percebido e o desejado do que os subordinados eficazmente liderados.

\section{FUNCIONÁRIOS MENSALISTAS}

Em todas as dimensð̃es, o clima ideal é superior ao atual (real), que, em média, está um pouco acima da metade da escala $(6,29)$ enquanto o ideal está no grau 7,84 .

Quanto à percepção do clima real, o fator "apoio" obtém o índice mais baixo de resposta entre todas as variáveis $(5,29)$, sendo, também em relação a ele, encontrada a maior diferença $(3,23)$ entre a percepção real e o nível de aspiração dos funcionários mensalistas.

Quanto aos padrões, repete-se aqui o fato de que os integrantes dos níveis hierárquicos mais baixos percebem o clima mais positivamente do que seus superiores. Isso já foi encontrado por Souza (21), e também por Gavin (22) que, trabalhando com outro instrumento, pesquisou 140 bancários: os de níveis mais baixos tinham as percepções mais favoráveis sobre a clareza e a eficiência das estruturas organizacionais.

\section{FUNCIONÁRIOS HORISTAS}

Em toda as dimensões, o clima ideal é superior ao atual (real), que, em média, está um pouco acima da metade da escala $(5,69)$ enquanto o ideal está em 7,90.

Quanto à percepção do clima real, o índice mais baixo de resposta entre todas as variáveis é o obtido pelo fator "apoio" $(5,00)$, sendo também em relação a esta variável encontrada a maior diferença $(4,16)$ entre a percepção real e o nível de aspiração dos funcionários horistas.

$O$ pessoal com menos poder e de níveis hierárquicos mais baixos tem as tarefas mais es- truturadas e definidas pelo todo. Na empresa em estudo não participa da formulação das políticas e diretrizes da organização; e sua ambigüidade decisória é bem menor do que a do pessoal de nível hierárquico mais alto.

Segundo Souza, "é possivel que isso lhes dê (aos escalöes mais baixos) maior tranqüilidade, os torne menos críticos e assim avaliem mais favoravelmente o clima organizacional" (2).

No que se refere a recompensas, os funcionários (mensalistas e horistas) do nível hierárquico mais baixo também mencionam a necessidade de recompensa material, mas sua ênfase concentra-se na possibilidade de participarem mais, serem reconhecidos como elementos de valor que contribuem e que gostariam de contribuir mais "se fôssemos ouvidos".

Quanto ao "calor humano e apoio", os grupos que apresentam as maiores discrepâncias entre a percepção real e ideal do clima são os funcionários horistas e mensalistas. Referem-se essencialmente a dificuldades de relacionamento com o nível de supervisão. Possibilidades de crescimento profissional e segurança quanto à manutenção do emprego também foram mencionadas.

Nota-se aqui uma adesão muito grande dos

18. SOUZA, Edela. Clima e Cultura Organizacionais: como se manifestam e como se manejam. $O p$. cit., p. 21.

19. LITWIN, G.A. e STRINGER, R.A. Jr. Op. cit.

20. HAETINGER, Yolanda F. Op. cit.

21. SOUZA, Edela. Clima e Cultura Organizacionais: como se manifestam e como se manejam. Op. cit., p.59.

22. GAVIN, James F. "Organizational Climate as a Function of Personnel and Organizational Variables" in: Journal of Applied Psychology, Washington, 60(1): 135-139, 1975.

23. SOUZA, Edela. "Percepção do clima Conforme o Escalăo Hierárquico". Op. cit., p. 53.

24. LAING, R. D. The Politics of the Family, New York, Vintage, 1972, p. 90 apud SOUZA, Edela. Clime e Cultura Organizacionais: como se manifestam $e$ como se manejam. Op. cit., p.59. 
elementos de supervisão aos valores e padrões da família, conforme citado por Laing (24), bem como à cultura étnica identificada por Souza (25) e Lewin (26). Percebe-se maior identificação nos horistas pelo fato de estarem há mais tempo na empresa (família) e de vários serem germânicos de nascimento ou origem.

Os chefes de divisão mencionam em relação ao fator "calor humano e apoio", necessidades de definição de estrutura e responsabilidades de cada um, atuação mais integrada dos diversos níveis e áreas, além de treinamentos e diversas atividades fora do trabalho.

Seria interessante citar a contribuição de Townsend (27) a respeito da definição da estrutura, item tão apontado pelos níveis superiores da empresa em estudo neste fator de "calor humano e apoio": "... organograma, instrumento extremamente útil para modelar os aspectos formais da estrutura, porém ilusório quando aplicado na tentativa de compreender o grupo $e$ o sistema, bem como terrivelmente. limitado quando utilizado para disciplinar as relações humanas ali embutidas" (28).

\section{CONCLUSÃO}

Obtém-se a caracterização dos tipos de clima predominantes nos diversos níveis hierárquicos, onde se evidencia que cada nível hierárquico possui características e necessidades próprias. No entanto, chama atenção o fato de formaremse basicamente dois grupos: um é o grupo hierarquicamente mais alto, composto por chefes de divisão, assessores e supervisores mensalistas; já o outro é formado pelos supervisores horistas, funcionários mensalistas e horistas.

Esses grupos divergem basicamente em termos da percepção do clima real, sendo que o escalão mais baixo percebe o clima mais favoravelmente do que o escalão mais alto.

Diagnosticou-se que os graus de satisfação variam em termos do nível hierárquico, sendo que os supervisores horistas apresentam a menor discrepância entre a percepção real e ideal do clima, enquanto os assessores revelaram a maior discrepância encontrada.

De maneira geral, aqui também se pode concluir que, na empresa em estudo, os funcionários de níveis hierárquicos mais altos (chefes de divisão, assessores e supervisores mensalistas) são os mais insatisfeitos com o clima, enquanto os de níveis mais baixos (supervisores horistas, funcionários mensalistas e horistas) estão mais satisfeitos.

Baseando-se nas informações obtidas através do feedback dos dados, conclui-se que a insatisfação nos níveis mais altos é gerada principal- mente por indefiniçס̃es de estrutura e de papéis, além de um subaproveitamento dos indivíduos deste nível e de baixo investimento nos mesmos.

Já nos níveis hierárquicos mais baixos, a organização é percebida com mais clareza, mas ressentem-se muito de calor humano e apoio.

Identificou-se que os motivos sociais de McClelland se concentram quase que homogeneamente em dois grandes grupos (os mesmos referidos anteriormente).

No grupo hierarquicamente mais alto os motivos encontrados, em ordem de prioridade, foram: realização, afiliação e poder. No grupo hierarquicamente mais baixo, foram: afiliação realização e poder. Excetua-se aqui o nível dos funcionários mensalistas, onde se encontraram: afiliação, poder e realização.

Conclui-se que os dados obtidos através da aplicação do instrumento de Kolb e alii e do feedback possibilitaram implantar várias medidas administrativas na área de Recursos Humanos.

Já em relação à empresa como um todo, e considerando o total da população pesquisada, verificou-se que as maiores discrepâncias entre o clima real e o ideal referem-se a:

1) calor humano, apoio e recompensas, baseados em motivaçðes afiliativas, que estão exigindo incentivos de caráter social para sua satisfação;

2) motivos de caráter realizador (clareza organizacional, padrões e responsabilidade) que indicam necessidade de maiores definições em relação aos objetivos da empresa, ao papel de cada um dentro destes objetivos e ao seu relacionamento com as outras divisóes dentro da própria empresa; e

3) motivos de poder (liderança e conformidade) que, na empresa familiar em estudo, estão indicando a necessidade de uma descentralização por parte do empresário, possibilitando aos indivíduos melhor capacitados e/ou potencialmente desenvolvidos maiores espaços para ação/decisão.

25. SOUZA, Edela. Clima e Cultura Organizacionais: como se manifestam e como se manejam. Op. cit., p.59.

26. LEWIN, K. Resolving Social Conflits. New York, Harper e Brothers, 1984, p. 51 apud SOUZA, Edela. Clima e Cultura Organizacionais: como se manifestam e como se manejam. Op. cit., p. 61.

27. TOWNSEND, Robert. Viva (Morra) a Organização. São Paulo, Melhoramentos, 1979.

28. Idem, ibidem, p. 45. 


\section{ANEXO 1}

\section{Levantamento do Clima Organizacional}

Para cada uma das sete dimensões do clima da organização descritas abaixo, coloque $R$ (Real) sobre o que indica a sua estimativa da posição atual da organização quanto a essa dimensão e I (Ideal) sobre o número que indica sua escolha de onde a organização deveria estar quanto à mesma dimensão.

1. Conformidade - O sentimento de que existem muitas restriçðes impostas pela organização; o grau em que seus membros sentem que existem muitas regras, procedimentos, diretrizes e práticas que têm de ser seguidas tirando sua liberdade de fazer o trabalho como eles acham que deveriam ser.
Conformidade não é uma ca-
$\begin{array}{lllllllllll}1 & 2 & 3 & 4 & 5 & 6 & 7 & 8 & 9 & 10\end{array}$
Conformidade é muito ca- racterística dessa organi- zação. racterística dessa organi- zação.

2. Responsabilidade - E dada responsabilidade pessoal aos membros da organização pelo cumprimento de sua parte para a consecução dos objetivos de organização; o grau que os membros sentem que podem tomar decisőes e resolver problemas sem consultar seus superiores a todo o momento.
Nenhuma responsabilidade $\quad \begin{array}{llllllllll}1 & 234567 & & \end{array}$ é dada na organizaçăo. responsabilidade pessoal.

3. Padrões - A ênfase que a organização coloca em desempenho de alta qualidade e produtividade superior, inclusive o grau em que o membro sente que a organizaçăo está estabelecendo metas estimulantes para si mesma e transmitindo o comprometimento com esses objetivos aos seus membros.

Os padrões são muito baixos. $\quad \begin{array}{lllllllll}1 & 2 & 4 & 5 & 6 & 8 & 9 & 10\end{array}$

Metas bastante desafiadoras são propostas na organização.

4. Recompensa - O grau em que os membros sentem que săo reconhecidos e recompensados por bom trabalho, ao invés de serem ignorados, criticados ou punidos quando algo sai errado.

Membros såo ignorados pu- $\quad 12345678910$

Membros são reconhecidos e nidos e criticados. recompensados positivamente.

5. Clareza Organizacional - O sentimento entre membros de que as coisas eståo bem organizadas e os objetivos estão claramente definidos, ao invés de serem desordenados, confusos ou caóticos.
A organização é desordena-
1233456789810
A organizaçăo é bem organi- zada com objetivos clara- mente definidos.

6. Calor humano e apoio - O sentimento de que a amizade é uma norma valorizada na organização; que os membros confiam uns nos outros e oferecem apoio uns aos outros. $O$ sentimento de que boas relações prevalecem no ambiente de trabalho.
Não há calor humano nem $\quad 122345678910$
apoio na organização
Calor humano e apoio são muito característicos da orga- nização.

7. Liderança - O desejo dos membros da organização de aceitarem a liderança e direção de outros membros mais qualificados.

Quando a necessidade de uma liderança surge, os membros se sentem em liberdade de aceitarem papéis de liderança e são recompensados por uma liderança bem-sucedida. A liderança é baseada em capacidade. A organização não é dominada nem dependente de um ou dois indivíduos apenas.

Liderança nåo é recompensada: membros são dominados ou dependentes e resistem a tentativas de liderança. $\begin{array}{llllllllll}1 & 2 & 3 & 4 & 5 & 6 & 7 & 8 & 9 & 10\end{array}$

Membros aceitam e recompensam a liderança baseada em capacidade. 